\title{
TEM Analysis of a Thermal Sprayed Steel
}

\author{
J. Hangas and A.D. Roche
}

Ford Motor Company, Scientific Research Lab, MD 3182, PO Box 2053, Dearborn, MI 48121

Thermal sprayed steels offer the promise of being a lower cost alternative to conventional steel tooling for stamping sheet metal parts. The process uses a twin wire arc spray to spray the steel. The sprayed material can be deposited onto a substrate in complex shapes in a few hours by computer-controlled equipment. Relatively little machining has to be done afterwards. Scaling the process up to large parts requires understanding the residual stresses in the deposited material, which are in turn affected by the phase transformations that take place as the sprayed material solidifies and on cooling transforms from austenite to martensite or bainite. The rate of deposition controls the temperature of the sprayed deposit. The time required to deposit the material means substantial aging or tempering occurs that will alter the microstructure of the deposit.

The wire source material used in the process is a $38 \mathrm{~T}$ alloy with $0.8 \mathrm{wt} \% \mathrm{C}, 0.7 \mathrm{wt} \% \mathrm{Mn}, 0.1 \mathrm{wt} \% \mathrm{Si}$, and traces of $\mathrm{P}$ and $\mathrm{S}$. Spraying was done in a booth with flowing $\mathrm{N}_{2}$, but oxygen from the atmosphere does get in. The deposit consists of splats of steel with layers of magnetite between them as shown in the backscattered electron (BSE) image in Figure 1. Three samples were examined, two of which were sprayed in 40min with thermocouples in the ceramic substrate and IR monitoring the surface temperature of the spray form. One was $7.2 \mathrm{~mm}$ thick and the other was $13.8 \mathrm{~mm}$ thick, the latter being made with almost double the gun current of the former. Thermal measurements indicate that the temperature of the surface was about $225^{\circ} \mathrm{C}$ in the thin sample, and about $350-375^{\circ} \mathrm{C}$ in the thick sample. The third sample was $33 \mathrm{~mm}$ thick but not grown under such controlled conditions that the temperatures are known. Three millimeter disks were punched out of slices made perpendicular to the plane of deposition. The disks were tripod polished on both sides. The second side was polished at a $2^{\circ}$ wedge angle so that the splats are perpendicular to the edge. The sample was then ion milled in a Gatan PIPS at $3 \mathrm{keV}$.

Figure 2 shows a dark field image taken with a $\{211\} \theta-\mathrm{Fe}_{3} \mathrm{C}$ reflection at the $[100]_{\alpha^{\prime}}$ zone axis of a tempered martensite lath from the $7.2 \mathrm{~mm}$ thick sample. There are fine rod-like intragranular cementite particles, and some cementite decorating grain boundaries. Some spherical intragranular $\mathrm{Fe}_{3} \mathrm{O}_{4}$ particles are also present (marked by arrow). The $13.8 \mathrm{~mm}$ thick sample had a grain structure that was a mixture of equiaxed grains and laths with long carbides between the laths. A small area of laths with intergranular carbides is shown in Figure 3A, consistent with a tempered martensite. The temperature of this sample during spray forming is close to the $\mathrm{M}_{\mathrm{s}}$ temperature, and further work analyzing the bainite content of the sample is in progress. Spherical particles are also common in the splats, due to droplets solidifying before they impact the sample surface. Figure 3B shows such a particle in the thick sample that has colonies of laths and carbides, as well as some small oxide particles. The third sample that was examined was $33 \mathrm{~mm}$ thick and had transverse intragranular cementite precipitates with one orientation variant in an equiaxed ferrite grain (Figure 4). The transverse carbides are consistent with lower bainite, as are the long laths with carbides between at the top of the image. The [001] $\alpha^{\prime}$ SAD pattern is similar to the one taken for the area in Figure 2, but the coarser $\theta-\mathrm{Fe}_{3} \mathrm{C}$ precipitates yield brighter $\theta-\mathrm{Fe}_{3} \mathrm{C}$ reflections. The $\mathrm{Fe}_{3} \mathrm{O}_{4}$ reflections in Figure $4 \mathrm{~b}$ arise from native oxide layers which grow on the foil [1]. 
[1] Y. Ohmori and I. Tamura, Met. Trans. A, 23A, (1992) 2737-51.

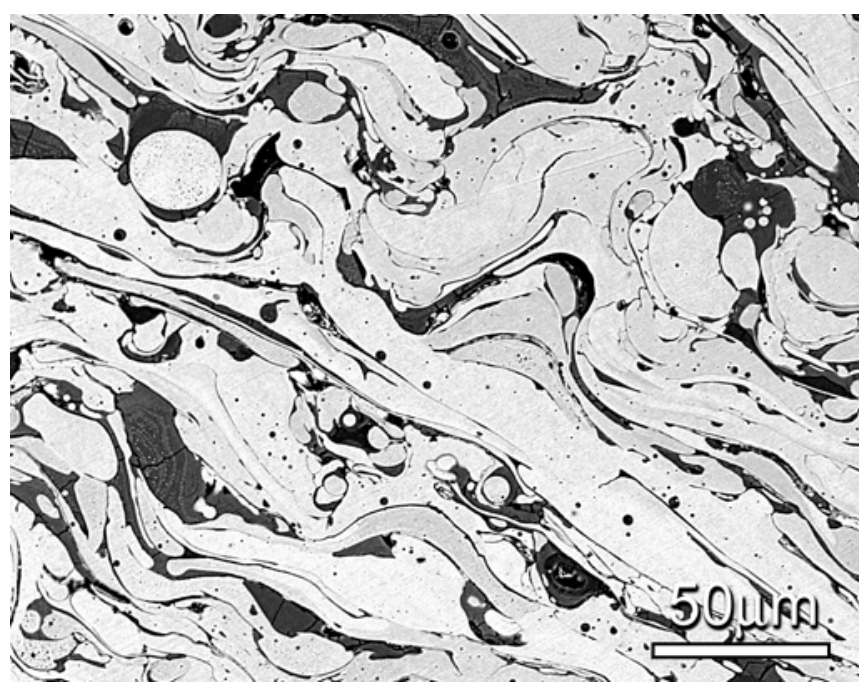

Figure 1. BSE image of splats in $7.2 \mathrm{~mm}$ thick sample. Oxides between metal splats are dark grey. Some variation is seen in density of metal.

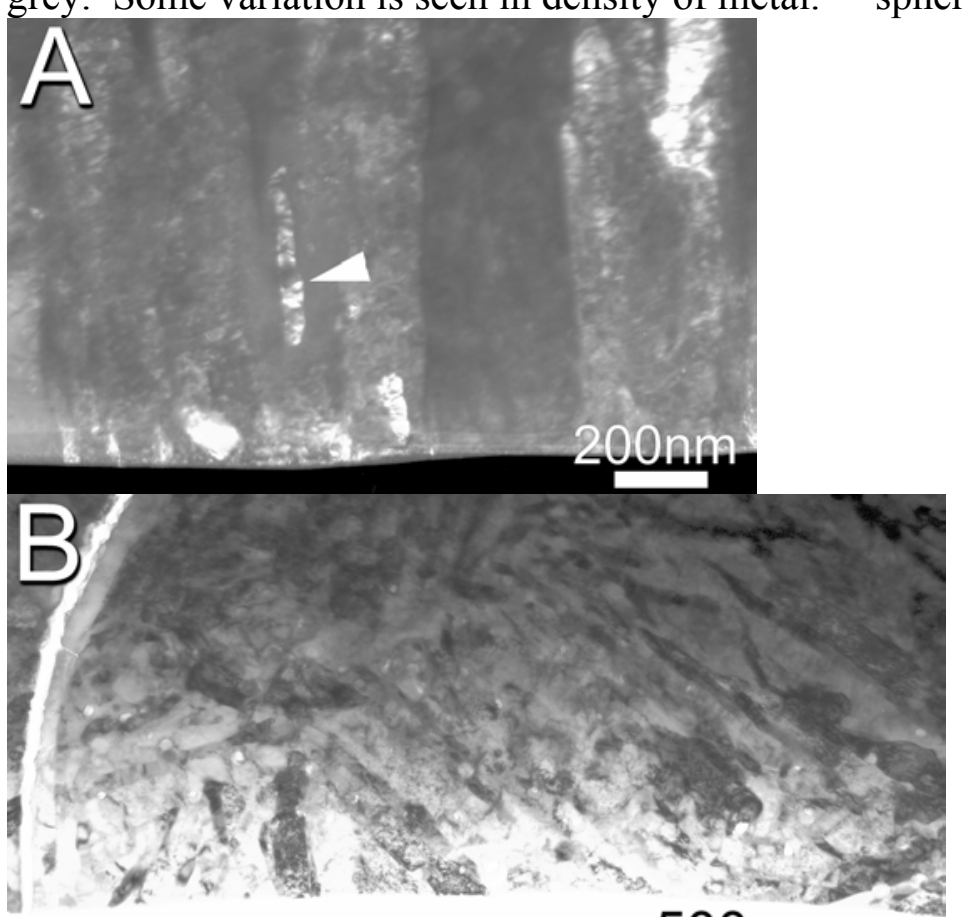

$500 \mathrm{~nm}$

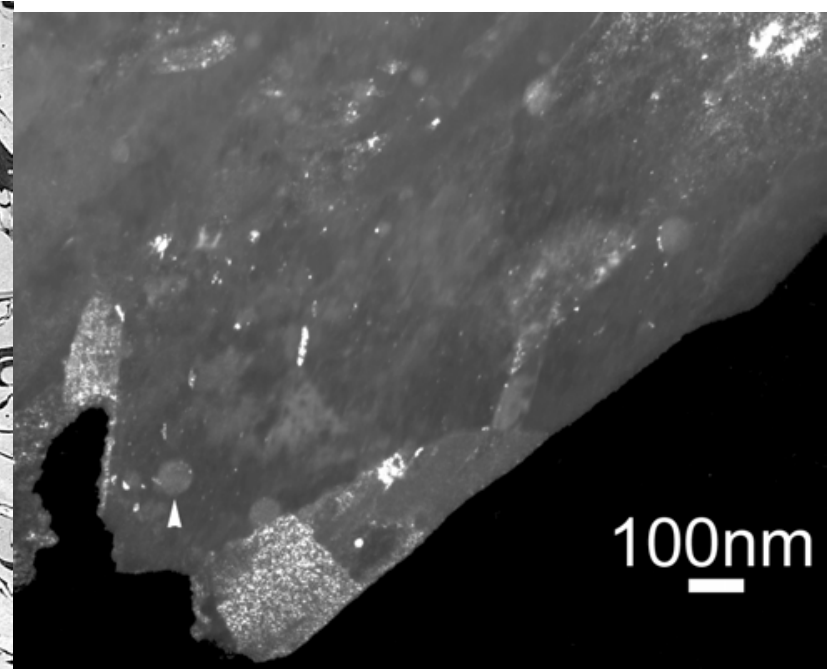

Figure 2. DF from tempered martensite in $7.2 \mathrm{~mm}$ thick sample. The arrow points to a spherical, out of contrast $\mathrm{Fe}_{3} \mathrm{O}_{4}$ particle. 

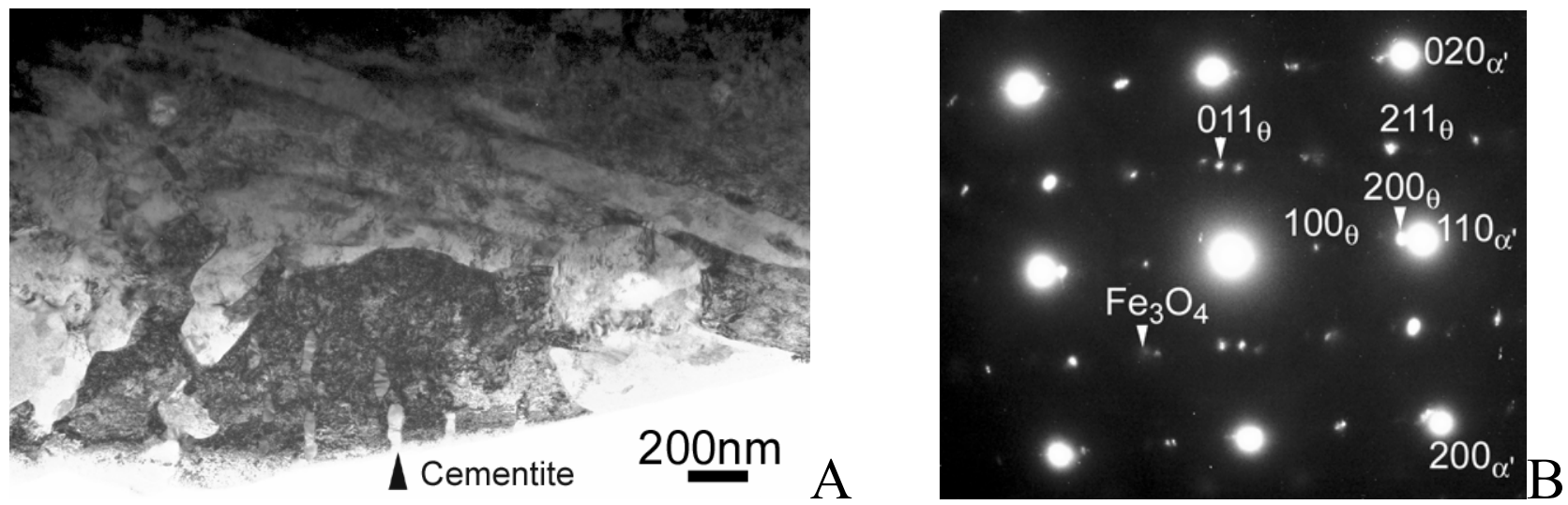

Figure 4. A) BF TEM image of one orientation variant of intragranular cementite $(\theta)$ particles in a ferrite matrix (consistent with lower bainite). The long laths at the top are separated by carbides. B) $[001]_{\alpha^{\prime}}$ SAD pattern. 